\title{
Potencial dendrogeomorfológico de coníferas en volcanes del centro de México
}

\author{
Dendrogeomorphological potential of conifers on volcanoes of central Mexico
}

\author{
Osvaldo Franco-Ramos ${ }^{\text {a*}}$, Lorenzo Vázquez-Selem ${ }^{\text {a }}$, Markus Stoffel ${ }^{\text {b,c }}$, José Villanueva Díaz ${ }^{\mathrm{d}}$ \\ *Autor de correspondencia: a Universidad Nacional Autónoma de México, Instituto de Geografía, Ciudad Universitaria, \\ Coyoacán, 04510, Ciudad de México, México, tel.: +525556224240, ofranco@igg.unam.mx \\ ${ }^{\mathrm{b}}$ University of Geneva, Dendrolab.ch., Department of Earth Sciences, Rue des Maraîchers 13, CH-1205 Geneva, \\ Switzerland. \\ ${ }^{\mathrm{c}}$ University of Geneva, Climate Change and Impacts, Institute of Environmental Sciences, 7 route de Drize, \\ CH-1227 Carouge, Switzerland. \\ dNIFAP, CENID-RASPA, Gómez Palacio, Durango, Km 6.5 Margen Derecha del Canal Sacramento, \\ Gómez Palacio, Dgo. 35140, México.
}

\begin{abstract}
SUMMARY
Geomorphological processes can influence the growth of the forest or individual trees. Based on dendrogeomorphological methods, we analyzed growth disturbances on several conifers affected by lahars and rockfalls, namely: Pinus hartwegii, Pinus leiophylla, Pinus ayacahuite, Abies religiosa and Juniperus monticola, localized on volcanic terrains of central Mexico. We also studied the age of these species. The main visible damages on trees by lahars were burial (35\%) and wounds (34\%) of stems. The main growth disturbances on tree-rings are growth suppression (31\%) and tangential rows of traumatic resin ducts $(30 \%)$. In the case of rockfalls the most common visible damages on trees were wounds $(61 \%)$ and decapitation or loss of apex $(20 \%)$. The main growth disturbances were growth suppression (51\%), growth release (16\%) and injuries $(15 \%)$. The trunks of young trees had a superior number of impacts due to lahars and falling rocks than those presented by long-lived trees. Trees of A. religiosa have better dendrogeomorphological potential than Pinus spp. since they form tangential rows of traumatic resin ducts and are more sensitive to impacts and burial by rocks and sediment. For the determination of the minimum age and the stabilization period of landforms, the conifers analyzed were useful for up to hundreds of years, mainly Pinus hartwegii (500-600 years old) and Juniperus monticola (800-850 years old). Results show that dendrochronological methods can be useful in the study of geomorphological processes on temperate forests of central Mexico.
\end{abstract}

Key words: dendrogeomorphology, lahars, rockfalls, landform minimum age, central Mexico.

\section{RESUMEN}

Los procesos geomorfológicos pueden alterar el crecimiento natural de un rodal o de un árbol. A base de métodos dendrogeomorfológicos se analizaron disturbios en árboles afectados por lahares y caída de rocas en Pinus hartwegii, Pinus leiophylla, Pinus ayacahuite, Abies religiosa y Juniperus monticola, localizados en áreas volcánicas del centro de México. Los daños visibles más comunes en los árboles afectados por lahares fueron: sepultamiento de troncos (35\%) y heridas de impacto (34\%). Los disturbios más comunes encontrados en los anillos de crecimiento fueron: supresiones en crecimiento (31\%) y filas tangenciales de ductos de resina traumáticos (TRD) (30\%). En los árboles afectados por caída de rocas, los daños visibles más frecuentes fueron: impactos $(61 \%)$ y decapitación (20 \%). Los disturbios más comunes en los anillos de crecimiento fueron: supresiones (51\%), realces (16\%) y cicatrices de impacto (15\%). Los troncos de los árboles jóvenes presentaron mayor número de impactos por lahares y caída de rocas que los árboles más longevos. Abies religiosa tiene mejor potencial dendrogeomorfológico que Pinus spp., ya que forma TRD y es más sensible a impactos y sepultamientos por rocas y sedimento. Para el estudio de edades mínimas de relieve y de estabilización geomorfológica, las especies analizadas fueron útiles para eventos de decenas a cientos de años atrás, destacando P. hartwegii (500-600 años) y J. montícola (800-850 años). Los métodos dendrocronológicos para estudios de procesos geomorfológicos tienen un buen potencial en bosques templados del centro de México.

Palabras clave: dendrogeomorfología, lahares, caída de rocas, edades mínimas de relieve y centro de México.

\section{INTRODUCCIÓN}

De acuerdo con Selby (1982), en ambientes de montaña los procesos de remoción en masa son de los fenóme- nos más frecuentes y peligrosos. Se trata de movimientos masivos de roca, suelo, vegetación que ocurren en laderas inclinadas $\left(>20^{\circ}\right)$, favorecidos por la gravedad y desencadenados por factores geológicos, climáticos y antrópicos. 
Los principales tipos son: caída de rocas, deslizamientos, avalanchas, vuelcos, reptación, y flujos de escombros, conocidos como lahares cuando el proceso ocurre en ambientes volcánicos (Vallance 2000). La mayor parte del centro de México presenta relieve geológicamente joven, construido durante el Cuaternario y se caracteriza por el predominio de sistemas montañosos de origen volcánico y una tectónica activa (Lugo-Hubp 1990). Esta condición sugiere que los procesos geomorfológicos deben ocurrir con cierta frecuencia, sobre todo en áreas geomorfológicamente activas, con escasa vegetación e importantes cambios de uso de suelo, afectadas por fenómenos hidrometeorológicos como los huracanes provenientes del Océano Pacífico y Golfo de México.

En los sistemas montañosos volcánicos del centro de México, se tiene un amplio conocimiento de los tipos y características de los procesos de remoción en masa (Capra et al. 2003, Alcántara-Ayala 2004). Sin embargo, se conoce muy poco de lo que sucede con el bosque antes, durante o después de un evento geomorfológico en el interior de las cuencas hidrológicas, así como su frecuencia y magnitud, que en muchos casos puede ser buen indicador del origen, dinámica, poder destructivo y alcances de los procesos de remoción en masa en ambientes volcánicos (Bollschweiler et al. 2010).

La dendrogeomorfología estudia la relación entre los procesos geomorfológicos y los disturbios originados en los árboles afectados, es útil para fechar los eventos, determinar su magnitud, frecuencia y alcance espacial. La base de este método es la relación proceso-evento-respuesta, donde el proceso corresponde a los fenómenos geomorfológicos que se llevan a cabo en un tiempo y espacio determinados como caídas de roca, lahares, flujos de escombro, inundaciones, avalanchas de nieve, etc. (Stoffel y Bollschweiler 2008). El evento se considera cuando un árbol o rodal son afectados por alguno de los procesos mencionados. La forma de afectación puede ser impactos, inclinación, sepultamiento, o decapitación, entre otros. La respuesta es el tipo e intensidad del disturbio en los anillos de crecimiento, como cicatrices de impacto, filas tangenciales de ductos de resina traumáticos (TRD, por sus siglas en ingles), madera de reacción, supresión en crecimiento, realce en crecimiento, anillos excéntricos y tejidos callosos (Stoffel y Corona 2014).

En los últimos años, la dendrocronología se ha aplicado de muchas maneras para entender la dinámica de diversos fenómenos geológicos y geomorfológicos, incluyendo el análisis de la frecuencia y magnitud de caídas de rocas (Trappmann y Stoffel 2015), la reconstrucción espacio-temporal de flujos de escombros (Salaorni et al. 2017) y la determinación de edades mínimas de nuevos relieves (Pierson 2007, Kroh et al. 2008, Koch 2009). En México, los estudios dendrocronológicos de varias coníferas de ambientes templados y subtropicales han demostrado que estas forman anillos anuales bien definidos que pueden alcanzar edades de varios siglos, y son idóneas para estudios paleoambientales, destacando el caso de $T a$ xodium mucronatum Ten., que alcanza más de mil años (Villanueva et al. 2010). Varias de las especies utilizadas en análisis dendroclimáticos también podrían utilizarse para reconstruir procesos morfodinámicos $\mathrm{y} / \mathrm{o}$ para determinar periodos de estabilización-desestabilización geomorfológica en laderas y barrancos. Los trabajos pioneros de dendrogeomorfología son los realizados en terrenos volcánicos del centro de México por Bollschweiler et al. (2010), Stoffel et al. (2011) y Franco-Ramos et al. (2013, 2016ab, 2017ab).

Los objetivos centrales de este estudio son (i) exponer el potencial dendrocronológico de algunas especies de coníferas del centro de México para fechar eventos geomorfológicos del pasado reciente; (ii) conocer los tipos y cantidad de daños visibles en los troncos de árboles afectados por procesos geomorfológicos y (iii) el tipo y porcentaje de disturbios en los anillos de crecimiento de árboles afectados, (iv) relacionar la edad de los árboles con los disturbios por lahares y caída de rocas. Las hipótesis de este trabajo son dos: la primera, que los árboles que habitan las laderas de montaña inestables del centro de México son constantemente afectados por procesos geomorfológicos que alteran su crecimiento normal y edad. La segunda, que, a pesar de los problemas de crecimiento de los árboles afectados por procesos, estos se pueden fechar y son útiles para identificar disturbios en los anillos de crecimiento con una resolución anual y permiten estimar edades mínimas del relieve y estabilización geomorfológica.

\section{MÉTODOS}

Sitios de estudio. En el área de estudio se analizaron sitios de trabajo que se localizan en terrenos volcánicos del centro de México (figura 1). En las barrancas Huiloac, Nexpayantla y Pelagallinas-La Venta del volcán Popocatépetl, entre los 2.000 y 3.500 m s.n.m., se muestrearon árboles de Pinus hartwegii Lindl., Pinus ayacahuite Ehrenb., y Abies religiosa (Kunth) Schltdl. et Cham. En el valle El Rodadero, al norte del volcán Iztaccíhuatl sobre el límite superior del bosque ( $\sim 4.000 \mathrm{~m}$ s.n.m.), se colectaron árboles de P. hartwegii. En las barrancas Montegrande y La Arena al sur del volcán de Colima, alrededor de los 2.000 m s.n.m., se extrajeron muestras de árboles de Pinus leiophylla Schiede ex. Schltdl. et Cham. En la barranca Axaltzintle, al noreste del volcán La Malinche, a una altitud aproximada de $2.500 \mathrm{~m}$ s.n.m., se colectaron árboles de A. religiosa. En el valle La Teta al noroeste del volcán Cofre de Perote, sobre el límite superior del bosque ( $\sim 4.000$ m s.n.m.), fueron muestras de árboles de $P$. hartwegii. En el flujo de lava localizado al sur del volcán Pico de Orizaba, entre 4.000 y 4.500 m s.n.m., se muestrearon individuos vivos y principalmente muertos del arbusto alpino Juniperus monticola Martínez f. orizabensis Martínez. 
Estrategias de muestreo en campo. El muestreo dendrogeomorfológico se llevó a cabo en barrancas y laderas que presentaron signos de inestabilidad por procesos geomorfológicos, es decir, en árboles impactados, sepultados, inclinados, decapitados, en troncos con raíces expuestas por lahares (figura 2), en árboles con impactos por desprendimientos de roca (figura 3 ) y en individuos dispuestos sobre superficies geomórficas de aspecto reciente, como flujos de lava (figura 4), lóbulos de caída y al interior de barrancas para conocer los periodos de estabilización geomorfológica. En individuos impactados, las muestras se tomaron lo más cerca posible de la cicatriz de impacto, para observar con claridad la señal del evento geomorfológico (Stoffel y Corona 2014). En árboles inclinados se tomaron dos núcleos de madera en el ángulo máximo, una en el sector del tronco más expuesto al proceso morfológico a estudiar, con orientación ladera arriba (lado C) y la otra muestra del lado opuesto, que es la cara más protegida a los procesos y en dirección ladera abajo (lado D). La utilidad de colectar las caras C y D, es para identificar con mayor claridad la presencia de madera de reacción, supresión de crecimiento y/o crecimiento excéntrico de los anillos anuales (figura 5A). Los lados A y B también pueden ser afectados por algún proceso geomorfológico y son útiles para reconocer otras anomalías del pasado, así como para identificar anillos perdidos o falsos y precisar el co-fechado entre las muestras de cada árbol (figura 5A). En árboles sepultados, los núcleos se extrajeron lo más cerca posible del relleno detrítico o en la cara expuesta del tronco. Para estimar las edades mínimas de relieve y estabilización geomorfológica se colectaron núcleos y secciones transversales lo más cerca posible a la base del tronco, para poder tener la mayoría de los anillos de crecimiento y una edad del arbolado más precisa. Para la extracción de núcleos utilizamos barrenos Pressler de distinta longitud (figura 5B). Para la toma de secciones transversales y cuñas en árboles se empleó una motosierra eléctrica. En cada árbol se colectaron al menos dos muestras, buscando llegar a la médula para obtener todos los anillos.

En total se obtuvieron 1.174 muestras (cuadro 1), de las cuales 1.095 fueron núcleos de crecimiento o virutas (figura 5D), 62 secciones transversales (figura 5C) y 17 cuñas. En campo cada árbol muestreado fue posicionado mediante un GPS con un rango de error de $\pm 3 \mathrm{~m}$. En las barrancas del sur del volcán de Colima se colectaron 78 árboles vivos de $P$. leiophylla, En el Popocatépetl 68 árboles vivos de $A$. religiosa, $P$. hartwegii y $P$. ayacahuite

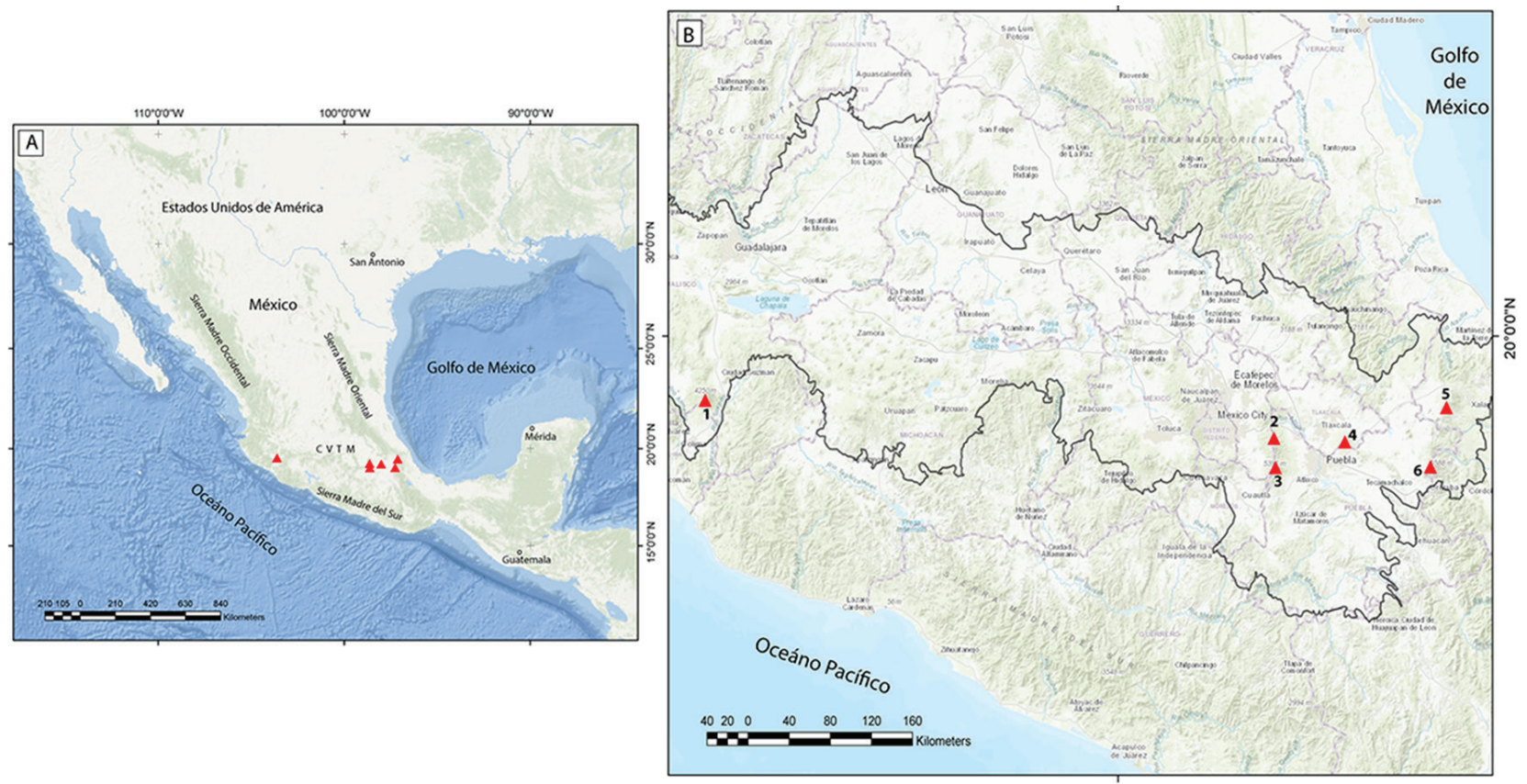

Figura 1. Localización del área y sitios de estudio. A) Principales provincias fisiográficas de México. El área de estudio se localiza en el centro de México, en la provincia volcánica Cinturón Volcánico Transmexicano (CVTM). B) Los sitios de estudio corresponden a terrenos volcánicos templados y sub-tropicales del CVTM (línea negra): 1 = Colima (3.860 m s.n.m.), 2 = Iztaccíhuatl (5.228 m s.n.m), 3 = Popocatépetl (5.460 m s.n.m.), 4 = La Malinche (4.461 m s.n.m.), $5=$ Cofre de Perote (4.282 m s.n.m.) y $6=$ Pico de Orizaba (5.640 m s.n.m.).

Location of study area and sampled sites. A) Main physiographic provinces of Mexico. The study area is on central Mexico namely Trans-Mexican volcanic belt. B) The sampled sites are on temperate and sub-tropical volcanic terrains (black line): $1=$ Colima $(3,860 \mathrm{~m}$ a.s.1.), $2=$ Iztaccíhuatl (5,228 m a.s.1.), 3 = Popocatépetl $(5,460 \mathrm{~m}), 4=$ La Malinche (4,461 m a.s.1.), $5=$ Cofre de Perote (4,282 m a.s.1) and $6=$ Pico de Orizaba (5,640 m a.s.1.). 
en la barranca Huiloac, 74 árboles vivos de $P$. hartwegii en la barranca Pelagallinas-La Venta, y 1,00 individuos vivos de A. religiosa en la barranca Nexpayantla. En La Malinche 86 árboles vivos en la barranca Axaltzintle. En el Iztaccíhuatl 24 especímenes vivos de $P$. hartwegii en el talud El Rodadero (volcán Iztaccíhuatl). En el Cofre de Perote, 1,10 árboles vivos de $P$. hatwegii en el talud La Teta. Finalmente, en el Pico de Orizaba, sobre el flujo de lava localizado en el lado suroeste del volcán, 27 individuos muertos y cinco vivos del arbusto alpino de $J$. monticola.
Análisis en laboratorio. En laboratorio las muestras fueron preparadas de acuerdo con criterios estandarizados para su conteo y fechado. Una vez que asignamos las fechas a cada anillo de crecimiento de todas las muestras, estas se midieron utilizando un microscopio estereoscópico, un micrómetro digital LINTAB (Rinntech 2016) y una de tipo VELMEX de precisión 0,001 (Robinson y Evans 1980). Para el análisis de correlación visual y co-fechado entre las series medidas para cada sitio de estudio, se utilizó el programa de análisis de series de tiempo TSAP-Win
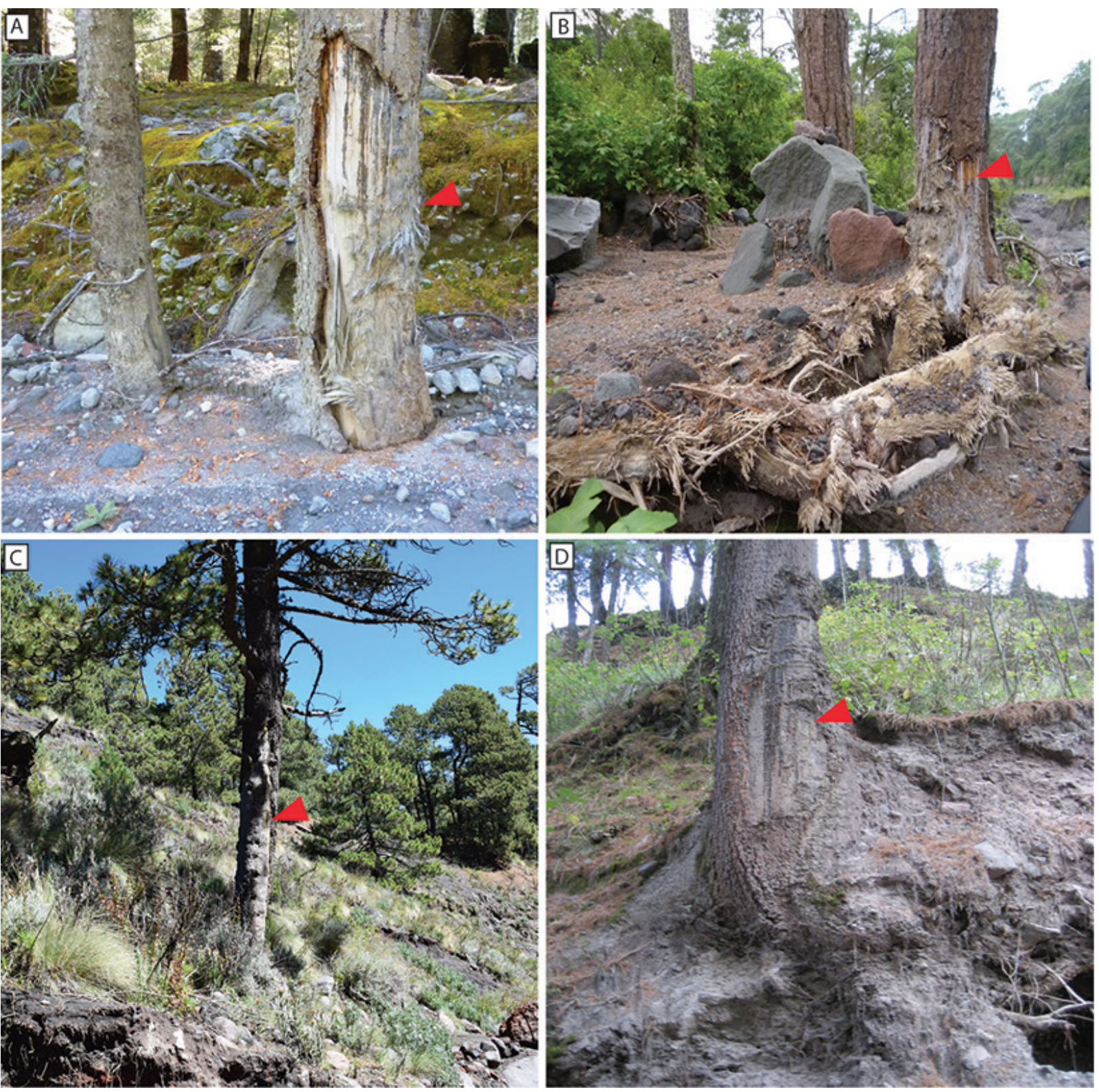

Figura 2. Disturbios en coníferas por lahares sin e intra-eruptivos: A) A. religiosa, volcán La Malinche, B) P. leiophylla, volcán de Colima, C) P. hartwegii y D) P. ayacahuite en el volcán Popocatépetl. Las flechas rojas indican la cara del tronco impactada.

Growth disturbances on conifers by syn-eruptive and post-eruptive lahars: A) A. religiosa on La Malinche volcano, B) P. leiophylla on Colima volcano, C) P. hartwegii; and D) P. ayacahuite on Popocatépetl volcano. Red arrows indicate the scars in the stem. 
(Rinntech 2016). Para la validación del fechado e intercorrelación de las series se utilizó el programa COFECHA (Holmes 1983). La edad de los árboles, la interpretación y el análisis de los disturbios en los anillos de crecimiento, asociados a procesos geomorfológicos (lahares y caída de rocas), se realizó con el conteo preciso de las muestras y la observación de las virutas y secciones, a través del microscopio estereoscópico $10 \mathrm{X}$ y siguiendo la propuesta de Stoffel y Corona (2014).
Para la estimación de edades mínimas de relieve y periodo de estabilización geomorfológica, a la edad máxima de cada árbol se le aplicó una calibración considerando la altura de la muestra, el número de anillos faltantes en el caso de no haber llegado a la médula, y el período de écesis que en ambientes volcánicos templados del centro de México ( $\sim 4.000 \mathrm{~m}$ s.n.m.), se estima que puede ser de entre 7 y 10 años (Franco-Ramos et al. 2017a).
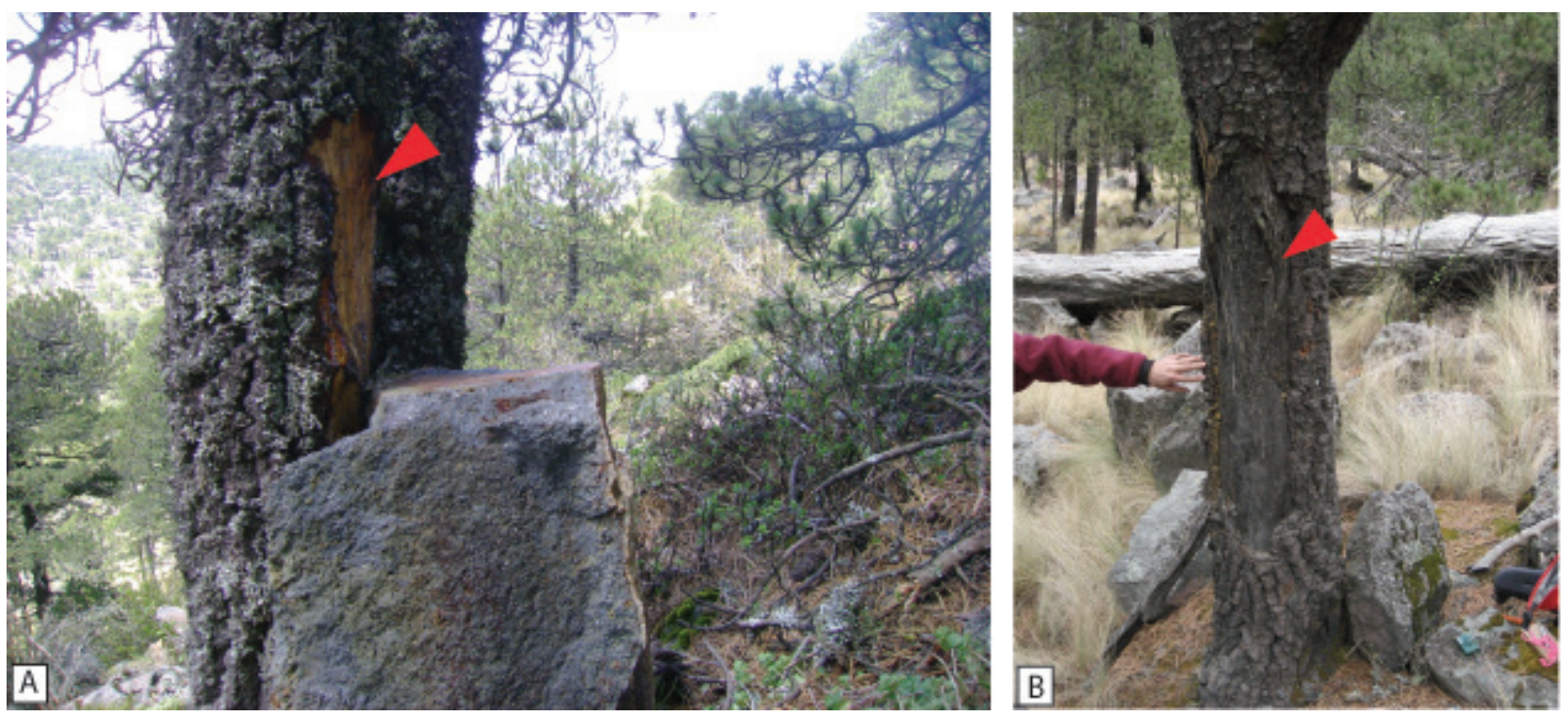

Figura 3. Impactos por caída de roca en los individuos de $P$. hartwegii, A) Talud detrítico del valle La Teta y B) Talud detrítico El Rodadero, Iztaccíhuatl. La flecha roja indica la cara del tronco impactada, en algunos casos aún se observa el bloque que impacto al árbol. Iztaccíhuatl volcano.

Scars on the stem of $P$. hartwegii by rockfall events. A) Detritic talus of Valle La Teta, Cofre de Perote; and B) detritic talus at El Rodadero,
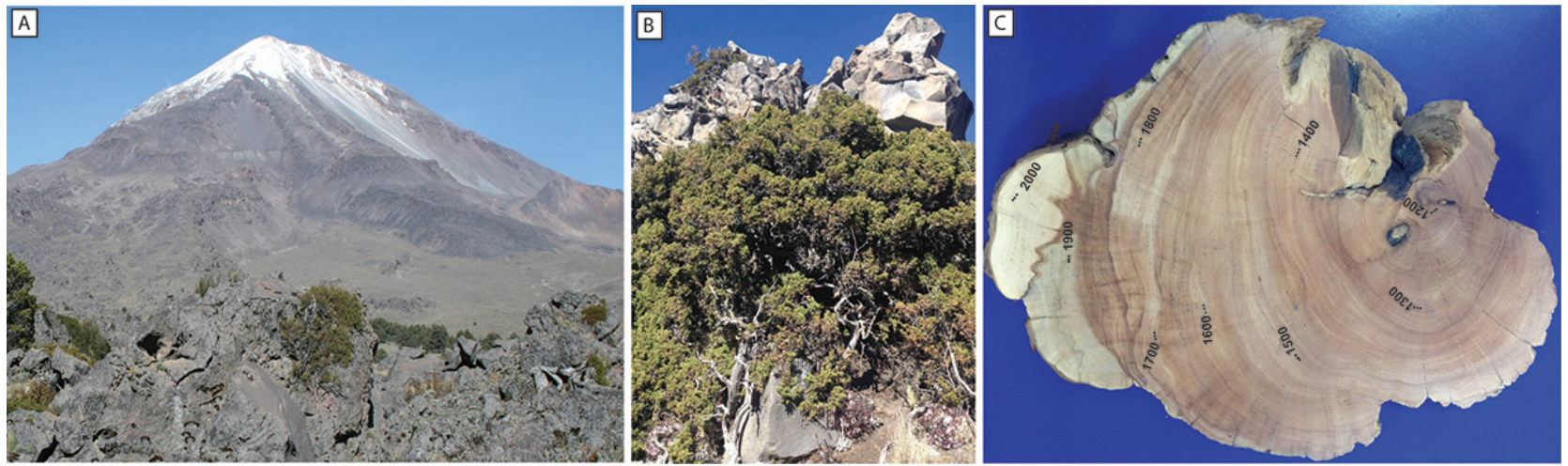

Figura 4. A) Flujo de lava al sur del volcán Pico de Orizaba, colonizado por J. monticola y P. hartwegii alrededor de los $4.000 \mathrm{~m}$ snm. B) Detalle del enebro J. monticola, sobre las crestas de lava. C) Sección transversal de un individuo de $J$. monticola con una edad superior a $\operatorname{los} 834$ años.

A) Lava flow on southern slope of Pico de Orizaba volcano colonized by Juniperus monticola and Pinus hartwegii. B) Detail of $J$. monticola above lava flow ridge. C) Cross section > 834 years old sample of $J$. monticola. 

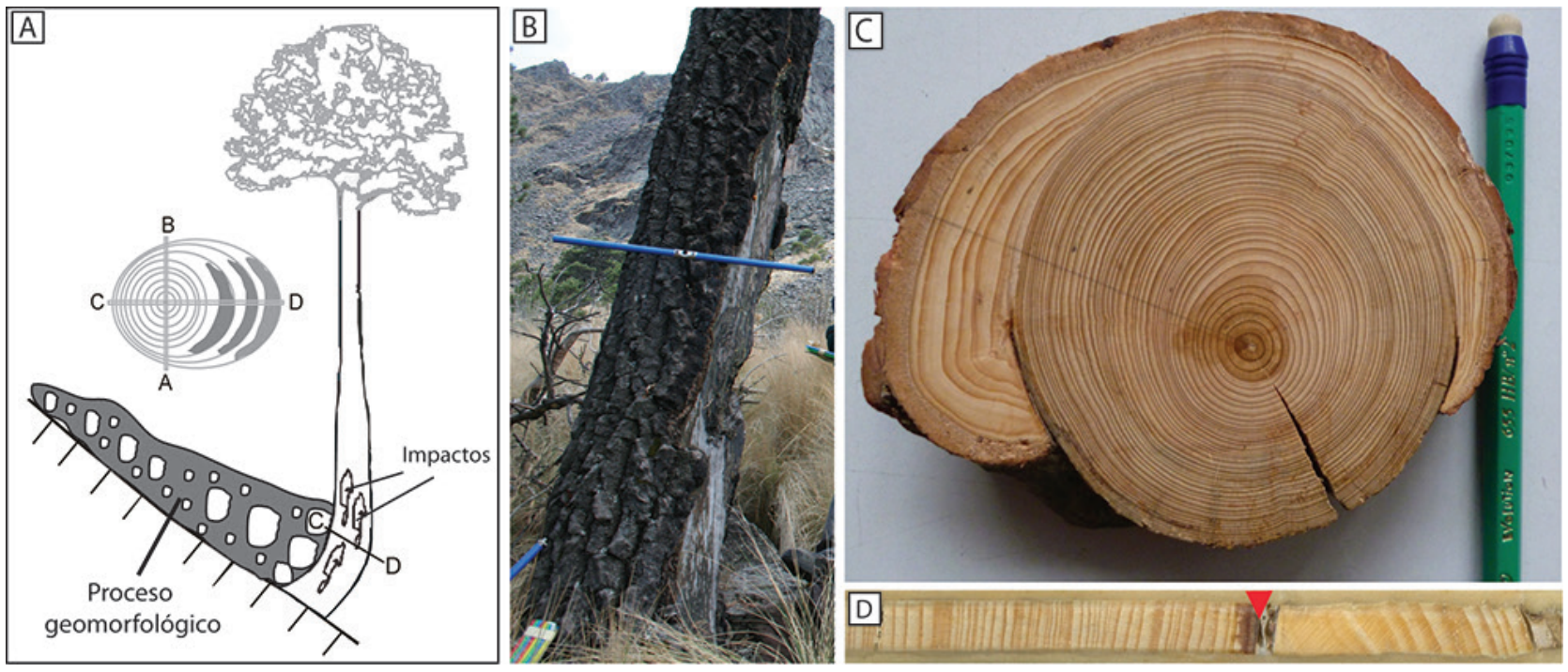

Figura 5. Para el análisis dendrogeomorfológico se utilizaron virutas, cuñas y secciones transversales. A) Caras del árbol utilizadas para el muestreo dendrogeomorfológico con base en los criterios de Stoffel y Bollschweiler, 2008. Núcleo en la cara "C" es la que mira hacia el origen del proceso. B) En árboles vivos con impactos se tomaron muestras muy cerca de la cicatriz, además se obtuvieron virutas de árboles sin disturbios para cronología de referencia. C) Las secciones transversales permiten visualizar un mayor número de disturbios, como el impacto ocurrido en este espécimen de $A$. religiosa en el año 2005 en el volcán La Malinche. D) Viruta de $P$. hartwegii del Cofre de Perote. La variabilidad en el ancho de los anillos de crecimiento y la cicatriz de impacto por caída de roca en 1998 (flecha roja), sugiere una sensibilidad climática y geomorfológica. Posterior al evento se identificaron anillos "ausentes" y realce en el crecimiento.

Different types of samples for dendrogeomorphological analyses. A) Sampling strategies based on Stoffel and Bollschweiler (2008). Core "C" is taken upslope. B) On live trees with damage we used increment borer close to the scars. C) Cross section on A. religiosa showing growth disturbances by a geomorphologic event in 2005 on La Malinche volcano. D) Increment core of $P$. hartwegii on Cofre de Perote volcano; the variability in tree-ring growth and the injury by rockfall dated in AD 1998 indicate the climatic and geomorphic sensibility of the tree.

\section{RESULTADOS}

Las distintas especies de coníferas que se analizaron en este estudio registraron edades que varían de decenas a cientos de años, sin superar los 1.000 años. Los árboles más viejos se encontraron en superficies geomorfológicas relativamente estabilizadas como terrazas altas, laderas de barranco y lóbulos de caída antiguos. En cambio, los individuos más jóvenes se reconocieron en superficies morfodinámicamente activas, como lechos fluviales, terrazas bajas y lóbulos de caída recientes. La especie analizada más longeva es el arbusto leñoso alpino $J$. monticola con edades superiores a 800 años, lo que la hace la segunda más longeva hasta ahora identificada en México (solo después de Taxodium mucronatum, Villanueva Díaz et al. 2010). En general se identificaron valores bajos de intercorrelación en las series dendrocronológicas de ancho de anillo en el programa COFECHA $(P<0,01)$. Los valores más altos de inter-correlación se obtuvieron en las series de P. leiophylla $(0,5)$ de las barrancas Montegrande-La Arena y en A. religiosa $(0,5)$ de la barranca Axaltzintle. Los valores intermedios de intercorrelación fueron en $A$. religiosa $(0,4)$ de la barranca Nexpayantla y las series de $J$. monticola $(0,4)$ del Pico de Orizaba. El valor más bajo de inter-correlación, se observó en las series de $P$. hartwegii $(0,3)$ en el talud detrítico del valle La Teta, Cofre de Perote (cuadro 1).

Disturbios en los anillos decrecimiento deárboles afectados por lahares en el centro de México. Los individuos más longevos para reconstruir lahares en el centro de México fueron los de P. leiophylla, muestreados en las barrancas Montegrande y La Arena al sur del volcán de Colima, con una edad promedio de $77 \pm 12$ años (árbol más viejo: 98 años). Los árboles más jóvenes se encontraron sobre las terrazas laháricas en el interior de las barrancas. En cambio, los árboles más viejos ( $\sim 100$ años) se encontraron afuera de las barrancas, que son los sitios más estables y protegidos por el paso de lahares y flujos piroclásticos. Los efectos visibles en los árboles de $P$. leiophylla más recurrentes en el interior de las barrancas, fueron troncos sepultados (49 $\%$ ), inclinados (33\%) y los individuos impactados solo fueron el $17 \%$ (figura $2 \mathrm{~B}$; cuadro 2), como resultado del paso constante de lahares post-eruptivos y sin-eruptivos. Los disturbios encontrados en los anillos de crecimiento fueron principalmente supresiones en el crecimiento con el $53 \%$ de los casos, seguido de tejidos callosos (14\%), realces en el crecimiento (11\%) y cicatrices de impacto (figura 6A) (10\%). 


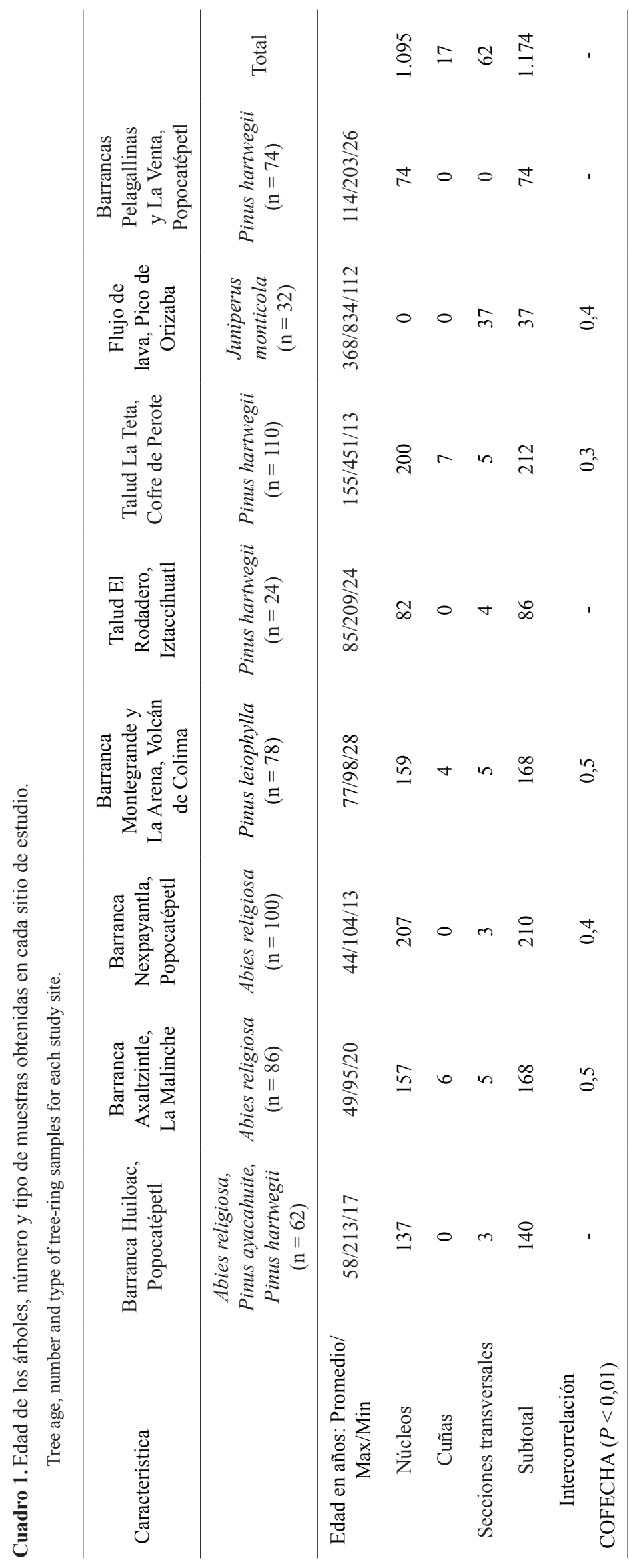


BOSQUE 39(2): 191-204, 2018

Potencial dendrogeomorfológico de coníferas

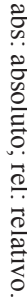

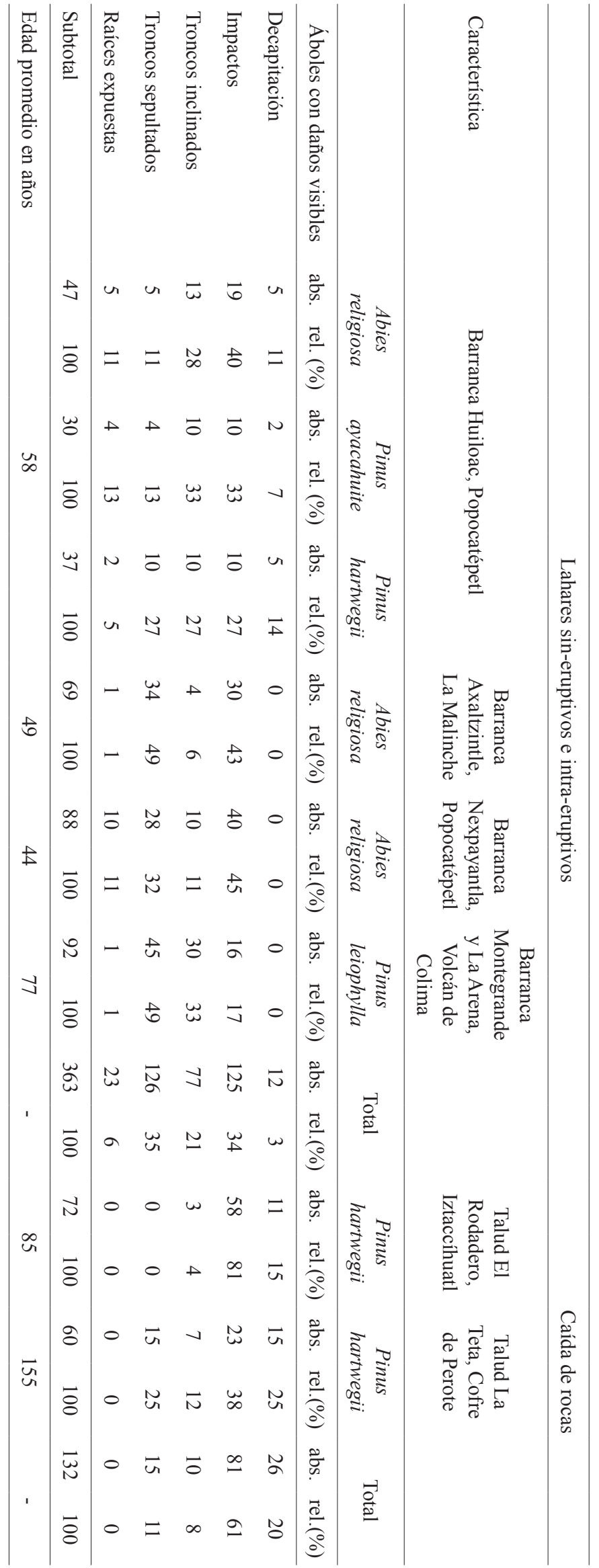

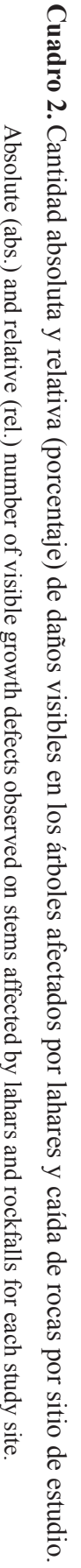



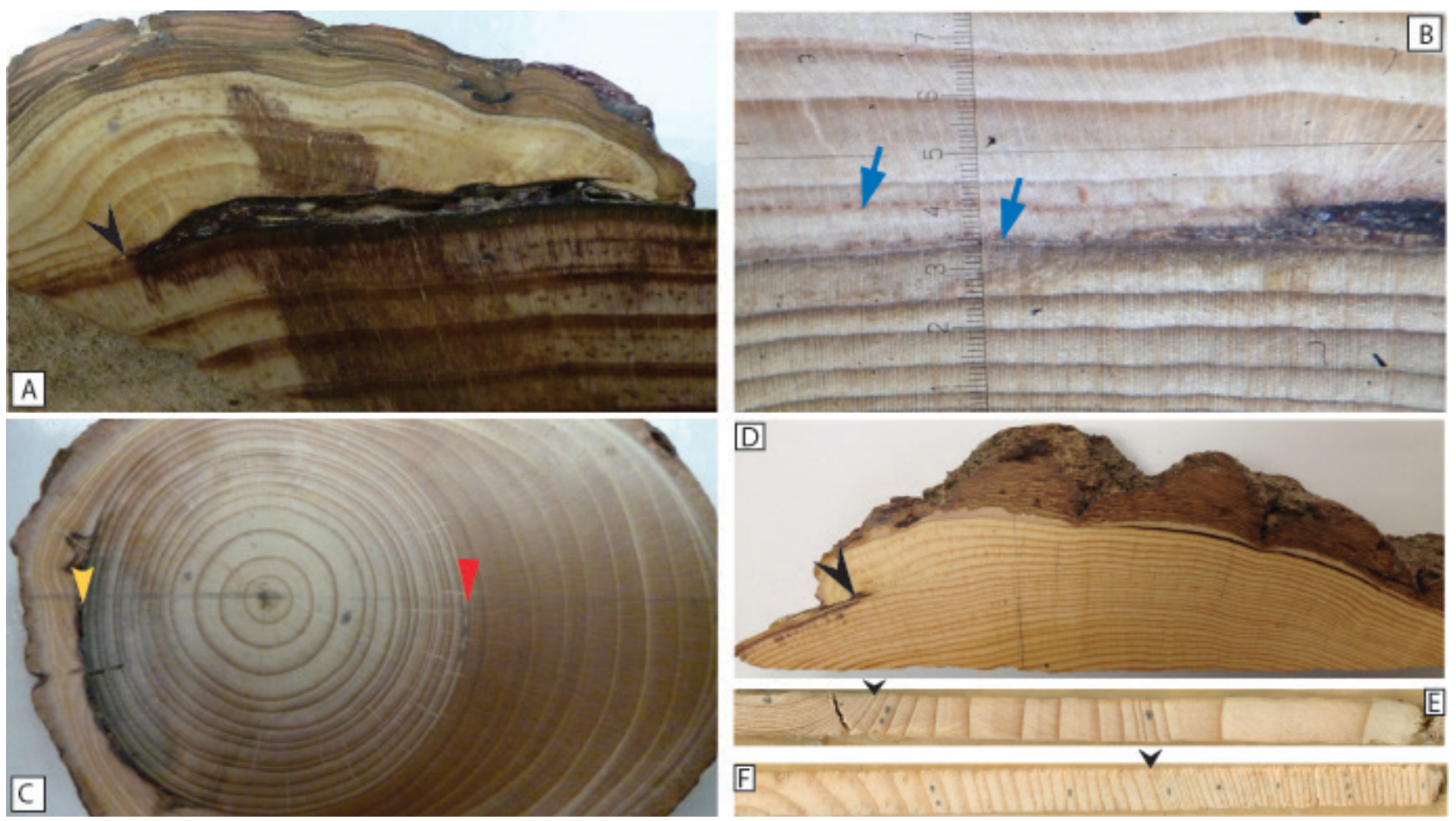

Figura 6. Principales disturbios en los anillos de crecimiento de los árboles afectados por procesos geomorfológicos como lahares y caída de rocas. A) Cicatriz de impacto en P. leiophylla en madera temprana del año 2005 (flecha negra), volcán de Colima. B) Cicatriz de impacto y ductos de resina traumáticos en A. religiosa en madera temprana del año 2005 (flechas azules), volcán Popocatépetl. C) Cicatriz de impacto (flecha amarilla), crecimiento excéntrico y madera de reacción (flecha roja) en A. religiosa en madera tardía del año 2001, volcán La Malinche. D) Cicatriz de impacto en P. hartwegii en madera tardía del año 2005 (flecha negra), volcán Cofre de Perote. E) Realce de crecimiento en A. religiosa en el año 1998 (flecha negra), volcán La Malinche. F) Crecimiento suprimido en $P$. hartwegii en año 1967 (flecha negra), volcán Cofre de Perote.

Main growth disturbances on trees affected by geomorphic processes such as lahars and rockfalls. A) Injury in the early wood period of 2005 on P. leiophylla, Colima volcano (black arrow). B) Injury and tangential row of traumatic resin ducts in the early wood period of 2005 on $A$. religiosa, Popocatépetl volcano (blue arrows). C) Injury (yellow arrow), eccentric growth and reaction wood (red arrow) in 2001 on $A$. religiosa, La Malinche volcano. D) Injury in P. hartwegii on late wood period in 1998, Cofre de Perote volcano (black arrow). E) Growth release in 1998 on $A$. religiosa, La Malinche volcano (black arrow). F) Growth suppression in 1967 on P. hartwegii, Cofre de Perote volcano (black arrow).

En la barranca Huiloac, localizada al NE del V. Popocatépetl, donde la edad promedio de los árboles analizados fue de $58 \pm 38$ años (árbol más viejo: 213 años). Las especies muestreadas fueron $P$. hartwegii, P. ayacahuite $y$ A. religiosa, en las cuales se observaron principalmente troncos impactados, inclinados y sepultados por bloques y sedimento provenientes de los lahares que se emplazan en la cara norte del volcán (figura 2C, D). La especie A. religiosa fue la más sensible a presentar heridas en las caras expuestas del tronco con el 40 \% (cuadro 2). En relación con las cicatrices de impacto identificadas en los anillos de crecimiento, el principal disturbio encontrado en $A$. religiosa fueron las columnas tangenciales de ductos de resina traumáticos (54\%), disturbio que prácticamente fue nulo en los pinos de la barranca Huiloac. El disturbio más común identificado en $P$. hartwegii fue la madera de compresión (31\%) y supresiones en crecimiento de anillo (24\%). En $P$. ayacahuite fueron las supresiones en crecimiento (39\%) y realces en crecimiento $(25 \%)$ (cuadro 3 ).
En la barranca Nexpayantla (volcán Popocatépetl) se encontraron los rodales más jóvenes de $A$. religiosa, con edades promedio de $44 \pm 17$ (árbol más viejo: 104 años), de los cuales $45 \%$ presentaron impactos visibles y el $32 \%$ eran troncos sepultados por detritos y sedimento (cuadro 2). De este modo, los principales disturbios identificados en los anillos de crecimiento de $A$. religiosa en los dos sitios de estudio fueron los ductos de resina traumáticos ( $48 \%$ y $39 \%$, respectivamente) (figura 6B), supresiones en crecimiento ( $30 \%$ y $23 \%$, respectivamente) y cicatrices de impacto con el $10 \%$ y $22 \%$ respectivamente (cuadro 3). Sin embargo, en algunos árboles de A. religiosa inclinados se observó madera de compresión y anillos excéntricos (figura $6 \mathrm{C}$ ) y realces en crecimiento (figura $6 \mathrm{E}$ ).

En las barrancas Axaltzintle (volcán La Malinche) la edad promedio de $A$. religiosa, fue de $49 \pm 16$ años (árbol más viejo: 95 años). Si bien, en estos dos sitios los disturbios por procesos geomorfológicos fueron muy recientes (solo de algunas decenas de años atrás), la ventaja del 
BOSQUE 39(2): 191-204, 2018

Potencial dendrogeomorfológico de coníferas

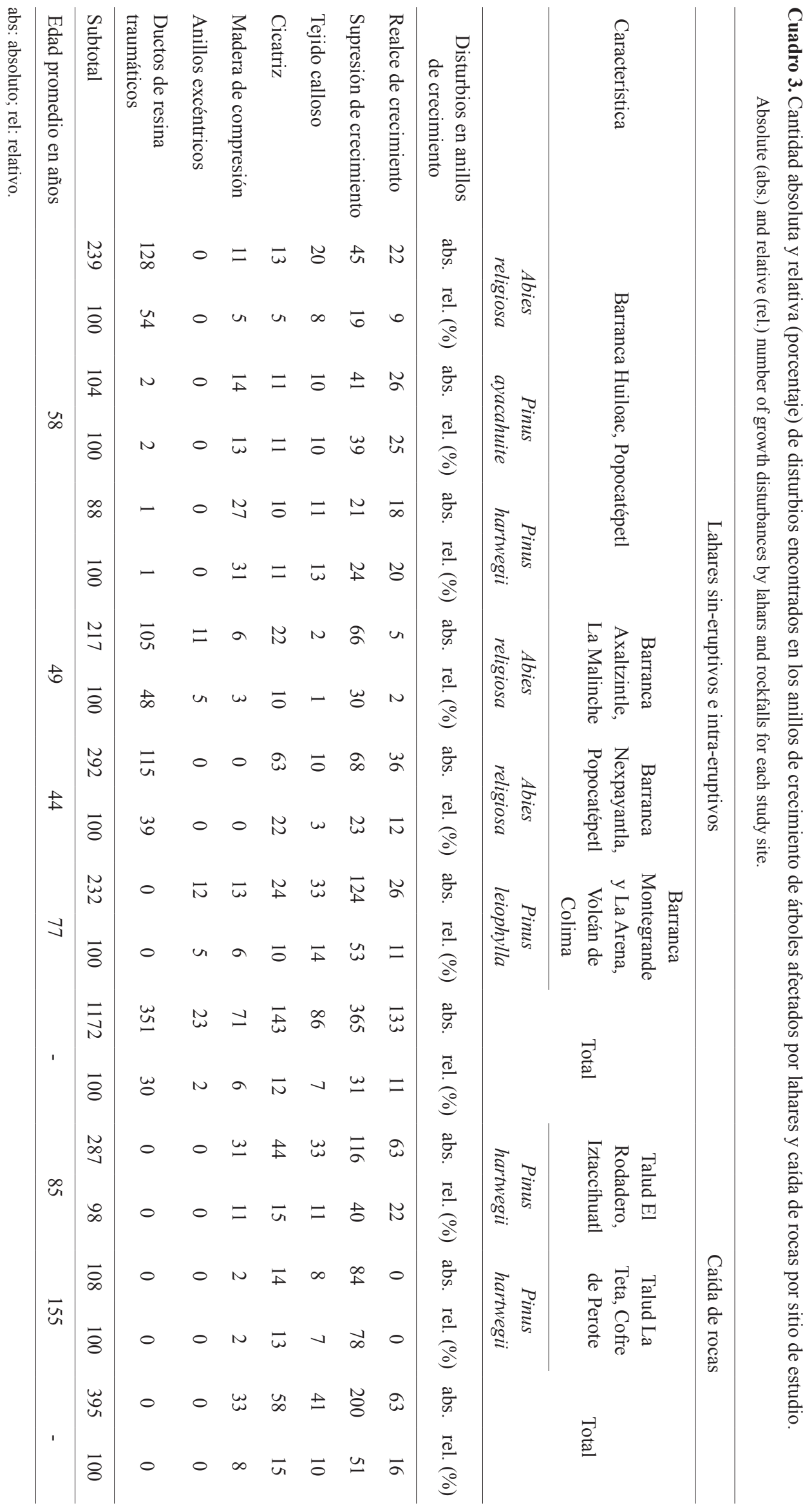


A. religiosa es que es altamente sensible a los efectos ocasionados por lahares. En la barranca Axaltzintle se observó en campo que el $49 \%$ de los individuos estaban sepultados por bloques y sedimento y el $43 \%$ de los troncos estaban impactados (figura 2A).

Disturbios en los anillos de crecimiento de árboles afectados por caída de rocas en el centro de México. En el talud detrítico del valle La Teta, se encontró un bosque de $P$. hartwegii relativamente maduro, con una edad promedio de los árboles de $155 \pm 91$ años (árbol más viejo: 451 años), incluso se pueden encontrar algunos individuos con una edad de 600 años o más. En este sitio se observaron muchos árboles claramente perturbados por los desprendimientos de bloques (figura 3A), el $38 \%$ de ellos presentaron heridas en las caras de los troncos expuestas, en el $25 \%$ se observaron árboles decapitados y en el otro $25 \%$ troncos sepultados por detritos y bloques. El $12 \%$ restante fueron troncos inclinados (cuadro 2). En ese sentido, los disturbios más frecuentemente identificados en $P$. hartwegii fueron las supresiones súbitas en el crecimiento $(78 \%$ ) (figura $6 \mathrm{~F}$ ), seguido de las cicatrices de impacto (13\%) (figura 6D) y tejidos callosos (7\%).

Otro sitio con una dinámica geomorfológica y dendrocronológica similar al talud detrítico del valle La Teta, fue el talud detrítico El Rodadero (norte del Iztaccíhuatl). Aquí los árboles de $P$. hartwegii fueron más jóvenes con una edad promedio de $85 \pm 39$ años (árbol más viejo: 209 años). Los desprendimientos de roca que ocurren en la zona han afectado el crecimiento de la vegetación arbustiva y arbórea. El $81 \%$ de los árboles muestreados presentaron heridas visibles en alguna cara del tronco (figura 3B). El $15 \%$ de los individuos fueron decapitados y solo en el $4 \%$ restante observamos troncos con inclinación (cuadro 2). Los disturbios en los anillos de crecimiento identificados fueron, en primer lugar, supresiones en crecimiento con el $40 \%$, seguido de realces en crecimiento $(22 \%)$, cicatrices de impacto ( $15 \%$ ), tejido calloso (11\%) y madera de compresión (11\%).

Edad mínima de relieves y estabilización geomorfológica. El flujo de lava que se encuentra al sur del Pico de Orizaba ( 4.000 m s.n.m.), está colonizado por P. hartwegii de $\sim 200$ años. Por encima de los 4.000 m s.n.m. predomina J. monticola con una edad promedio de $368 \pm 157$ años (figura 4A), muchos de los arbustos están muertos posiblemente por algún incendio forestal en los periodos de sequía. Sin embargo, se encontró que el individuo vivo más longevo tiene 834 años. De este modo se puede decir que la edad mínima del flujo de lava es de $\sim 850$ años (figura 4B).

La variabilidad en las edades de los árboles localizados al interior de las barrancas Pelagallinas-La Venta (norte del Popocatépetl), se pudo relacionar con los periodos de estabilización geomorfológica. La edad máxima encontrada en los árboles supera los $\sim 200$ años, por lo general son individuos que se localizan en las laderas de los barrancos, geomorfológicamente más estables que las cabeceras y lechos fluviales. Por ejemplo, en un sector de la barranca Pelagallinas (figura 7A) se observa un individuo de $P$. hartwegii de $\sim 118$ años en el lecho aluvial, sin daños o disturbios en el tronco, lo que sugiere que en esta barranca no han ocurrido procesos de incisión vertical ni acumulación de sedimentos significativos en los últimos $\sim 120$ años. Por otro lado, la presencia de árboles en las cabeceras de estos barrancos, indica la ausencia de procesos geomorfológicos importantes desde hace al menos $\sim 95$ años.

Además, la edad del arbolado fue útil para relacionar y comparar las edades de los distintos lóbulos da caída de rocas, como el caso del talud detrítico del valle La Teta, NW
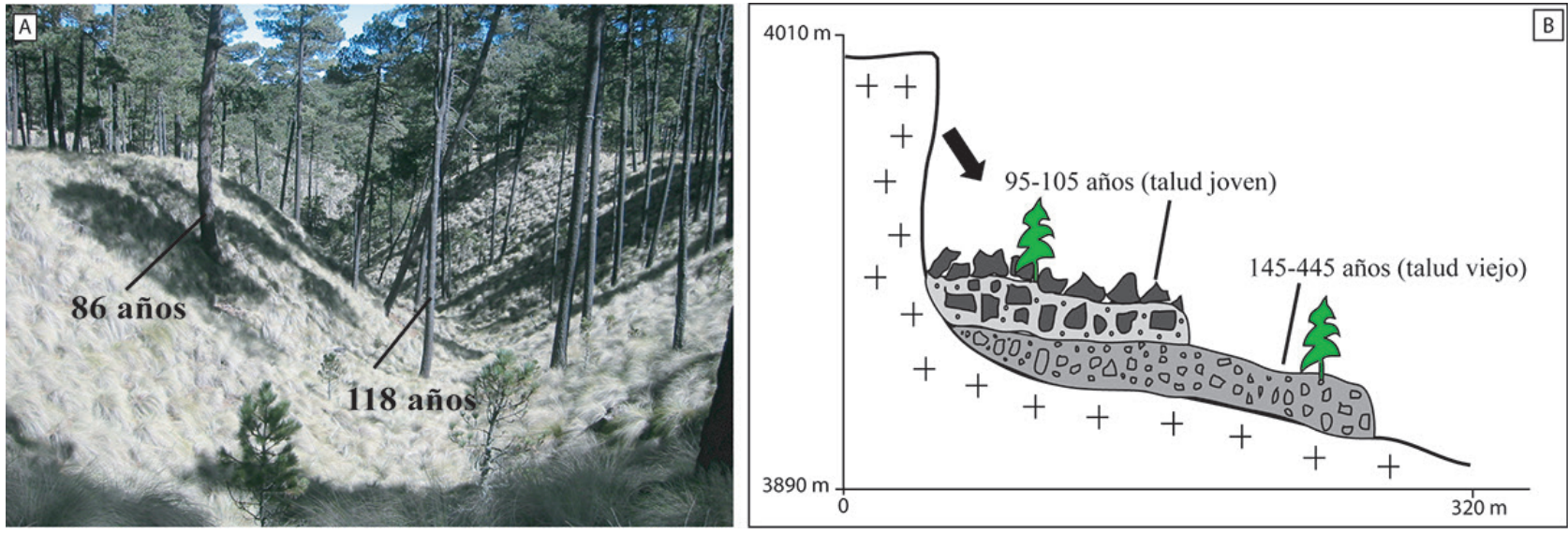

Figura 7. Edades mínimas de relieve y de estabilización geomorfológica con base en la edad del arbolado de $P$. hartwegii. A) Barranca Pelagallina norte del volcán Popocatépetl y B) Talud detrítico del valle La Teta, NW del volcán Cofre de Perote.

Landforms and stabilization geomorphic minimum age based on tree age of $P$. hartwegii. A) Pelagallina gorge, northern slope of Popocatépetl volcano. B) Detritic talus at La Teta valley on NW slope, Cofre de Perote volcano. 
del volcán Cofre de Perote (figura 7B), donde las edades de los individuos de $P$. hartwegii muestran por lo menos dos etapas de formación de lóbulos detríticos. El lóbulo más antiguo tiene al menos $\sim 45$ años y el más reciente al menos $\sim 105$ años. Los árboles más viejos crecen sobre taludes detríticos con fuertes limitaciones edáficas, por lo que encuentran entre los rodales más longevos identificados en el centro de México.

\section{DISCUSIÓN}

En las laderas de montañas volcánicas del centro de México, existen condiciones de inestabilidad geomórfica, donde los árboles y la vegetación que habita en esos ambientes son afectados frecuentemente por lahares y caída de rocas. A partir del análisis dendrogeomorfológico de 1.174 muestras de anillos de crecimiento de P. hartwegii, P. ayacahuite, $P$. leiophylla y A. religiosa, se demuestra que estas especies tienen un buen potencial dendrocronológico para fechar procesos geomorfológicos, a pesar de las bajas inter-correlaciones arrojadas por el programa COFECHA (cuadro 1). Esta situación se debe a que las series de ancho de anillo se obtuvieron de árboles con importantes problemas de crecimiento, debido al efecto de procesos geomorfológicos como anillos excéntricos, supresiones abruptas, realces en crecimiento, tejidos callosos y cicatrices de impacto. En el caso de $P$. hartwegii en taludes detríticos del valle La Teta (Cofre de Perote), es significativo 0,3 $(P<0,01)$, sin embargo, la baja inter-correlación de las series puede deberse a que la especie presenta importantes problemas de crecimiento por otros factores ambientales como incendios, plagas y sequías (Cerano-Paredes 2017). En el caso de las barrancas Huiloac y Pelagallinas-La Venta en el Popocatépetl, así como en el sitio el Rodadero del Iztaccíhuatl las muestras no se midieron, solo se utilizaron para saber el número, tipo de daños y disturbios en los árboles, así como para el conteo de anillos y asignar edades mínimas de relieve y estabilización geomorfológica.

La edad de los árboles está determinada por la especie, pero se pueden relacionar otros factores externos como el clima, el espesor del suelo, la dinámica geomorfológica y el aprovechamiento antrópico. Los rodales más viejos se encontraron en el Pico de Orizaba con la especie J. monticola (368 años promedio), seguido del Cofre de Perote donde la edad promedio de los $P$. hartwegii es de 155 años. En cambio, el bosque más joven se encontró al interior de barrancas morfo-dinámicamente activas y cercanas a asentamientos humanos como el caso de la barranca Nexpayantla, Axalzintle y Huiloac, con edades promedio que van de 44 a 58 años (cuadro 1). En estos sitios se observó un mayor porcentaje de impactos por lahares ( $27 \%$ a $45 \%$ ), a diferencia de las barrancas del volcán de Colima donde la edad promedio es mayor (77 años) y solo se tiene el $17 \%$ de cicatrices. También se observó una diferencia significativa entre las especies de los árboles, por ejemplo, el $P$. hartwegii y $P$. leiophylla presentaron menor porcentaje de impactos que el $A$. religiosa. Una relación similar entre la edad de arbolado y daños en los troncos ocurre en los sitios afectados por caída de rocas, donde existe un mayor porcentaje de impactos ( $81 \%$ ) en el Rodadero, que es un bosque más joven ( 85 años promedio) que el talud detrítico del valle La Teta (155 años promedio), en donde solo el $38 \%$ de los árboles se observaron impactos (cuadro 2). En los disturbios encontrados en los anillos de crecimiento por lahares y caída de rocas se encontró una relación con la edad, las supresiones abruptas aumentan con la edad, en cambio, el tejido calloso y la madera de reacción disminuye con la edad del arbolado (cuadro 3). Estos resultados coinciden con trabajo de Šilhán et al. (2015), donde reportan que a menor edad los árboles presentan mayor número de disturbios en el tronco y reacciones en los anillos de crecimiento, ya que los jóvenes asimilan más eventos, incluso los de menor magnitud. Por otro lado, la especie del árbol también influye en el número de disturbios, ya que especies con xilema más duro y una corteza más gruesa y flexible, son más resistentes a los disturbios geomorfológicos.

La resolución del fechado de eventos puedes ser anual e incluso sub-anual, debido a que las especies tienen periodos de crecimiento muy marcados, siendo posible distinguir disturbios como impactos y TRD en las dos principales etapas de crecimiento, madera temprana y madera tardía, así como el periodo de dormancia. Sin embargo, en zonas volcánicas activas y muy dinámicas como las barrancas del sur del volcán de Colima, que en algunos años pueden presentar $\geq 10$ eventos en un solo año, el método dendrogeomorfológico permitirá reconstruir un mínimo de lahares, es decir, los árboles captarán la señal del o de los eventos de mayor magnitud. Lo anterior se debe a que no todos los depósitos de lahar tienen la misma dimensión para dañar a los árboles, y en muchos casos existen árboles en zonas más protegidas del paso de lahares.

Los TRD que únicamente se identificaron en la especie $A$. religiosa del centro de México, también se han observado en otras especies de abetos impactados como los Larix decidua Mill., Picea abies (L.) Krast. y Abies alba Mill. (Bollschweiler et al. 2008), y han sido muy utilizados para fechar y reconstruir flujos de escombros, avalanchas de nieve y caída de rocas, dado que estos ductos de resina se desarrollan radialmente a las cicatrices de impacto. Además, los A. religiosa abundan al interior de barrancas donde predomina la humedad, son más jóvenes, tienen corteza más delgada y flexible que los Pinus spp., lo que permite identificar daños visibles en los troncos por lahares. Capta mejor la señal geomorfológica en los anillos de crecimiento, como madera de compresión, supresiones abruptas y cicatrices de impacto, incluso asimila los eventos geomorfológicos de menor magnitud. Por lo tanto, es de las coníferas más sensibles del centro de México y con mayor potencial dendrogeomorfológico.

Después del ahuehuete (T. mucronatum) la especie más longeva hasta ahora conocida en el centro de México es 
el enebro alpino $J$. monticola, que habita en laderas rocosas en general por encima de los 4.000 m s.n.m. Recientemente se ha determinado que esta especie tiene buen potencial dendrocronológico, ya que forma anillos anuales bien definidos y responde principalmente a la temperatura y a la humedad de verano. Sin embargo, en muchos casos los anillos de crecimiento son irregulares y usualmente tiene anillos perdidos, lo que dificulta su fechado y correlación (Villanueva et al. 2016). Esta especie alcanza 900 años en el Cofre de Perote ${ }^{1}$, lo cual en combinación con su sensibilidad la hace útil para reconstrucciones dendroclimáticas, dendropirocronológicas, dendroecológicas y dendrogeomorfológicas (edades mínimas de relieves y reconstrucción de procesos).

El individuo más viejo de $J$. monticola encontrado en el flujo de lava al sur del Pico de Orizaba, tuvo una edad de 834 años, por la tanto se considera que el flujo de lava tiene al menos $\sim 840$ años. No obstante, el trabajo de Alcalá-Reygosa et al. (2018) muestra que este flujo de lava es más antiguo: 3.000 años A.P. según métodos cosmogénicos y $\sim 1.000$ años con base en liquenometría de la especie Rhizocarpon geographicum. Por lo tanto, es muy probable que los individuos muestreados de J. monticola, correspondan a varias generaciones posteriores al emplazamiento del flujo de lava. Parte de las limitaciones del método dendrocronológico, es la dificultad de fechar, de manera absoluta, los relieves mayores a mil años, debido en parte a la escasez de especies longevas y en parte a que en muchos casos no se conoce el periodo de écesis (tiempo que transcurre entre la estabilización geomórfica, la germinación de la especie y el crecimiento a la altura muestreada) (Pierson 2007, Kroh et al. 2008, Koch 2009). En las laderas del volcán Popocatépetl, se estima un periodo de écesis de 7 a 10 años para $P$. hartwegii, dependiendo de las características litológicas, edáficas, climáticas y de la cercanía con los árboles semilleros (Franco-Ramos et al. 2017a). Para J. monticola hasta ahora se desconoce la duración del periodo de écesis.

\section{CONCLUSIONES}

Las hipótesis de la presente investigación fueron validadas. Los daños visibles en la corteza de los árboles y el análisis de los disturbios asociados a una dinámica geomorfológica, permiten fechar con una resolución anual y/o sub-anual lahares y caída de rocas del pasado reciente, con miras a evaluar su frecuencia, magnitud y distribución. Sin embargo, la edad del bosque, la especie y la posición geomorfológica de los árboles influye en el tipo e intensidad de los disturbios. Además, la dendrogeomorfología es un método viable para estimar las edades mínimas en relieves jóvenes de las montañas volcánicas, con base en especies de amplia distribución en la zona como: P. leiophylla, P. ayacahuite, A. religiosa, P. hartwegii, y $J$. monticola.

\footnotetext{
1 Julián Cerano, comunicación personal.
}

Estos dos últimos con edades superiores a 500 años, cercanas incluso al milenio en el caso de $J$. monticola. A pesar de los logros alcanzados hasta ahora, aún falta por explorar el potencial dendrogeomorfológico de otras especies de árboles que habitan en las laderas medias y bajas de la misma región y que hasta ahora solo han sido estudiadas con fines dendroclimáticos, como T. mucronatum, así como algunas especies del genero Alnus y Quercus que también habitan en áreas geomorfológicamente inestables de los bosques del centro de México.

\section{AGRADECIMIENTOS}

Un agradecimiento especial a los revisores anónimos que con sus valiosos comentarios y sugerencias mejoraron sustancialmente este trabajo. Este estudio se llevó a cabo gracias al financiamiento de los proyectos PAPIIT-UNAM con claves: IA101117 y IN1092.

\section{REFERENCIAS}

Alcalá-Reygosa J, D Palacios, I Schimmelpfennig, L VázquezSelem, L García-Sancho, O Franco-Ramos, J Villanueva, JJ Zamorano. 2018. Dating late Holocene lava flows in Pico de Orizaba (Mexico) by means of in situ-produced cosmogenic 36Cl, lichenometry and dendrochronology. Quaternary Geochronology 47: 93-106. DOI: https://doi. org/10.1016/j.quageo.2018.05.011.

Alcántara-Ayala I. 2004. Hazard assessment of rainfall-induced landsliding in Mexico. Geomorphology 61: 19-40. DOI:10.1016/j.geomorph.2003.11.004.

Bollschweiler M, M Stoffel, D Schneuwly. 2008. Traumatic resin ducts in Larix deciduas stems impacted by debris flows. Tree Physiology 28: 255-263. DOI:10.1016/j.catena.2007.04.004.

Bollschweiler M, M Stoffel, L Vázquez-Selem, D Palacios. 2010. Tree-ring reconstruction of past lahar activity at Popocatépetl volcano, México. The Holocene 20(2): 265274. DOI: $10.1177 / 0959683609350394$.

Capra L, J Lugo-Hubp, N Dávila-Hernández. 2003. Fenómenos de remoción en masa en el poblado de Zapotitlán de Méndez, Puebla: relación entre litología y tipo de movimiento. Revista Mexicana de Ciencias Geológicas 20(2): 95-106.

Cerano Paredes J. 2017. Relación clima-incendios en el norte y centro de México: un enfoque dendrocronológico. Tesis de doctorado en Geografía. México DF, México. Instituto de Geografía, Universidad Nacional Autónoma de México. 399 p.

Franco-Ramos O, M Stoffel, L Vázquez-Selem, L Capra. 2013. Spatio-temporal reconstruction of lahars on the southern slopes of Colima volcano, Mexico- A dendrogeomorphic approach. Journal of Volcanology and Geothermal Research 267: 30-38. DOI:10.1016/j.jvolgeores.2013.09.011.

Franco-Ramos O, M Castillo, E Muñoz-Salinas. 2016a. Using tree-ring analysis to evaluate the intra-eruptive lahar activity in the Nexpayantla Gorge, Popocatépetl Volcano (Central Mexico). Catena 147: 205-215. DOI:10.1016/j. catena.2016.06.045. 
Franco-Ramos O, M Stoffel, L Vázquez Selem. 2016b. Treering based record of intra-eruptive lahar activity: Axaltzintle valley, Malinche volcano, Mexico. Geochronometria 43: 74-83. DOI:10.1515/geochr-2015-0033.

Franco-Ramos O, L Vázquez-Selem, JJ Zamorano-Orozco, J Villanueva-Díaz. 2017a. Edad, dinámica geomorfológica y tipología de barrancos en el sector norte del volcán Popocatépetl, México. Boletín de la Sociedad Geológica Mexicana 69 (1): 1-19.

Franco-Ramos O, M Stoffel, L Vázquez-Selem. 2017b. Treering based reconstruction of rockfalls at Cofre de Perote volcano, Mexico. Geomorphology 290: 142-152. DOI: 10.1016/j.geomorph.2017.04.003.

Holmes RL. 1983. Computer-assisted quality control in tree-ring dating and measurement. Tree-Ring Bulletin 43: 69-78.

Šilhán K, T Pánek, J Hradecký, M Stoffel. 2015. Tree-age control on reconstructed debris-flow frequencies: examples from a regional dendrogeomorphic reconstruction in the Crimean Mountains. Earth Surface Processes and Landforms 40: 243-251. DOI:10.1002/esp.3623.

Kroh GC, K McNew, JE Pinder. 2008. Conifer colonization of a 350-year old rock fall at Lassen Volcanic National Park in northern California. Plant Ecology 199: 281-294. DOI:10.1007/s11258-008-9432-z.

Koch J. 2009. Improving age estimates for late Holocene glacial landforms using dendrochronology - some examples from Garibaldi Provincial Park, British Columbia. Quaternary Geochronology 4: 130-139. DOI:10.1016/j.quageo.2008.11.002.

Lugo-Hubp J. 1990. El Relieve de la República Mexicana. Revista Mexicana de Ciencias Geológicas 9: 82-111.

Pierson T. 2007. Dating young geomorphic surfaces using age of colonizing Douglas fir in southwestern Washington and northwestern Oregon, USA. Earth Surface Processes and Landforms 32: 811-831. DOI:10.1002/esp.1445.

Rinntech. 2016. LINTAB (Precision - for every single tree ring) \& TSAP-Win (Time Series Analysis and Presentation for Dendrochronology and Related Applications). Version
4.64 for Microsoft Windows. Consultado 10 ene. 2016. Disponible en http://www.rinntech.de

Robinson WJ, R Evans. 1980. A microcomputer-based tree-ring measuring system. Tree-Ring Bulletin 40: 59-64.

Salaorni E, M Stoffel, O Tutubalina, S Chernomorets, I Seynova, A Sorg. 2017. Dendrogeomorphic reconstruction of lahar activity and triggers: Shiveluch volcano, Kamchatka Peninsula, Russia. Bulletin of Volcanology 79(6):1-19. DOI:10.1007/s00445-016-1094-4.

Selby MJ. 1982. Hillslope materials and Processes. Oxford, USA. Oxford University Press. 264 p.

Stoffel M, M Bollschweiler. 2008. Tree-ring analysis in natural hazards research - an overview. Natural Hazards and Earth System Sciences 8: 187-202. DOI:10.5194/ nhess-8-187-2008.

Stoffel M, M Bollschweiler, L Vázquez-Selem, O Franco-Ramos, D Palacios. 2011. Dendrogeomorphic dating of rockfall on low-latitude, high-elevation slopes: Rodadero, Iztaccíhuatl volcano, México. Earth Surface Processes and Landforms 36: 1209-1217. DOI:10.1002/esp.2146.

Stoffel M, C Corona. 2014. Dendroecological dating of geomorphic disturbance in trees. Tree-Ring Research 70(1): 3-20. DOI:10.3959/1536-1098-70.1.3.

Trappmann D, M Stoffel. 2015. Visual dating of rockfall scars in Larix decidua trees. Geomorphology 245: 62-72. DOI:10.1016/j.geomorph.2015.04.030.

Vallance JW. 2000. Lahars. In Sigurdsson H, BF Houghton, SR McNutt, H Rymer, J Stix eds. Encyclopedia of volcanoes. London, UK. Academic Press. p. 601-616.

Villanueva Díaz J, J Cerano Paredes, DW Stahle, V Constante García, L Vázquez Selem, J Estrada Avalos, J Benavides Solorio. 2010. Árboles longevos de México. Revista Mexicana de Ciencias Forestales 1(2): 7-29.

Villanueva-Díaz J, L Vázquez-Selem, A Gómez-Guerrero, J Cerano-Paredes, NA Aguirre-González, O Franco-Ramos. 2016. Potencial dendrocronológico de Juniperus monticola Martinez en el Monte Tláloc, México. Revista Fitotecnia Mexicana 39(2): 175-185. 